\title{
Growth and Lipid Composition of Some Dematiaceous Hyphomycete Fungi Grown at Different Salinities
}

\author{
By J. L. MULDER, ${ }^{*}$ M. A. GHANNOUM, L. KHAMIS AND \\ K. ABU ELTEEN \\ Department of Botany and Microbiology, Kuwait University, PO Box 5969, \\ Safat 13060, Kuwait
}

(Received 27 February 1989; revised 8 June 1989; accepted 4 September 1989)

\begin{abstract}
The growth of the dematiaceous hyphomycetes (darkly pigmented microfungi) Alternaria phragmospora, Alternaria chlamydospora and Ulocladium chartarum was altered by increasing concentrations of $\mathrm{NaCl}$ in the growth medium. $U$. chartarum demonstrated the greatest sensitivity to salinity changes: chlamydospora-like structures were common at $\mathrm{NaCl}$ concentrations $>5 \%$. Lipid analyses of these fungi are presented. Steryl esters and fatty acids were the main lipid classes in the apolar fractions. Phosphatidylethanolamine, phosphatidylglycerol and phosphatidylcholine were the main polar compounds. Most phospholipids decreased at higher salinity. The major fatty acid was oleic acid $(18: 1)$ which decreased at $10 \% \mathrm{NaCl}$. A similar pattern was observed for palmitic acid (16:0). Myristic acid (14:0) and myristoleic acids $(14: 2,14: 1)$ were detected in all isolates cultured at $10 \% \mathrm{NaCl}$.
\end{abstract}

\section{INTRODUCTION}

Grant \& Long (1981) stated that an extreme environment is one in which some organisms are successful and a majority are excluded. This is clearly demonstrated when considering obligate organisms. The situation is less clear when dealing with a changing environment supporting both obligate and facultative organisms. Kushner (1978) emphasized the importance of the facultative organism in elucidating the possible adaptive features and mechanisms which assist in the exploitation of a changing and stressful environment.

Solute-tolerant micro-organisms demonstrate different structural and biochemical responses to alterations in the solute concentration. Brown $(1972,1976)$ reported that the most important feature in sugar-tolerant yeasts was the accumulation of polyols in the cell. Similarly, Avron \& Ben-Amotz (1979) reported on the increasing levels of glycerol in the alga Dunaliella with an increase in $\mathrm{NaCl}$ concentration in the growth medium. In the fungus Dendryphiella salina, Wethered et al. (1985) reported increased levels of polyols when the fungus was grown in saline media.

Numerous investigations have concentrated on the structure and physiology of the halophilic and halotolerant bacteria, whereas the filamentous fungi have been relatively neglected. Combs et al. (1968) confined their studies to the effect of $\mathrm{NaCl}$ on the lipid content of the pathogenic yeast Candida albicans. Tresner \& Hayes (1971) reported on the tolerance of terrestrial fungi to $\mathrm{NaCl}$ in their environment, but did not explain what were the actual responses of these genera to increasing salinity. Apart from the study on Dendryphiella salina by Paton \& Jennings (1988) little information is available on the responses of dematiaceous hyphomycetes (darkly pigmented microfungi) to salinity changes even though as a group they are frequently isolated from saline soils and salt-marshes (Pugh, 1962; Moustafa, 1975; Radwan et al., 1984). Moustafa (1975), in a study of osmophilous (osmotolerant) fungi found in the salt-marshes of Kuwait, recorded fluctuating salinities ranging from $1 \cdot 2 \%$ to $24 \cdot 2 \%$ where crusts were frequently formed. Similarly, Al-Hasan et al. (1987) reported on the seasonal changes in salt-marshes. An organism 
from such an ecological niche may possess specific characteristics which help it to adapt to the changing environment. Thus the main objective of the present study was to investigate the effects of increasing concentrations of $\mathrm{NaCl}$ on the growth and structure of three dematiaceous hyphomycetes, which are present in naturally occurring environments with a fluctuating salt concentration as well as in the desert soils of Kuwait.

\section{METHODS}

Isolation of the microfungi. Ulocladium chartarum, Alternaria chlamydospora and Alternaria phragmospora were isolated from soil samples collected from the salt-marsh and surroundings in the Al-Khiran area situated south of Kuwait city. Isolation media included sea-water agar (SWA) (Norris et al., 1970) and potato-dextrose agar (PDA). Standard soil dilution techniques were used and isolates were purified on PDA plates. Pure isolates were maintained on PDA slants and stored at $4{ }^{\circ} \mathrm{C}$.

Growth studies. PDA was used in all growth studies. The varying saline concentrations were prepared by addition of appropriate amounts of $\mathrm{NaCl}$ to the media to yield final concentrations of $5 \cdot 0 \%, 7.5 \%, 10.0 \%, 12.0 \%$ and $14.0 \% . \mathrm{NaCl}$ was not present in the control agar growth plates.

Radial growth. Triplicate plates for each concentration and isolate were incubated at $25{ }^{\circ} \mathrm{C}$. Colony diameters were determined daily for a period of $21 \mathrm{~d}$.

Biomass. Triplicate nutrient broth shake cultures for each isolate and salinity were incubated at roomtemperature. After a $7 \mathrm{~d}$ period mycelial mats were harvested, washed and dried for determination of the total dry weights. This provided another measure of the growth rate at different salinities.

Light microscopy. Slide mounts, using lactophenol or occasionally lactophenol cotton blue, were made from colonies grown at the different $\mathrm{NaCl}$ concentrations. All observations and photography were done with an Opton research microscope.

Scanning electron microscopy (SEM). Samples were taken from both broth and agar cultures and fixed in $2.5 \%$

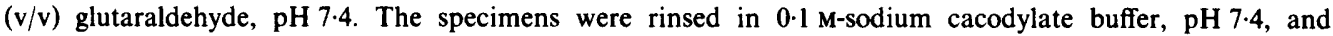
dehydrated by passing through an ethanol series. To guard against osmotic shock fixation was done in the growth medium by adding glutaraldehyde to give a final concentration of $2.5 \%$; the fixation period was $16 \mathrm{~h}$ at $4{ }^{\circ} \mathrm{C}$ (Cole, 1986). After critical-point drying and coating with palladium-gold [ $250 \AA(25 \mathrm{~nm})$ layer], the specimen was examined in a Novascan 30 stereoscan electron microscope.

Lipid extraction and analysis. Broth cultures at 0 and $10.0 \% \mathrm{NaCl}$ were incubated at $25{ }^{\circ} \mathrm{C}$ for $14 \mathrm{~d} ; 10.0 \% \mathrm{NaCl}$ was chosen on the basis of the evidence obtained in the growth studies. After $14 \mathrm{~d}$ all isolates were in the late exponential growth phase. There is no evidence to suggest that the lipid compositions change during this growth phase of the mycelium. At $10.0 \% \mathrm{NaCl}$ growth was less but there was still sufficient fungal mycelium for lipid extraction. Mycelium was harvested by centrifugation. Total lipids were extracted with chloroform/methanol $(2: 1, \mathrm{v} / \mathrm{v})$ and purified by standard methods (Folch et al., 1957). Non-polar lipids were resolved by chromatography on silica gel plates using hexane/diethyl ether/acetic acid $(90: 10: 1$, by vol.) as the solvent system (Mangold \& Malins, 1960). Polar lipids were resolved by two-dimensional TLC, using chloroform $/ \mathrm{methanol} / 7 \mathrm{M}$ ammonium hydroxide ( $65: 30: 4$, by vol.) as the solvent system in the first direction, and chloroform/methanol/acetic acid/water (170:25:25:4, by vol.) in the second direction (Nichols, 1964).

Lipid fractions were detected by iodine vapour or by charring at $220^{\circ} \mathrm{C}$ after spraying with aqueous $50 \%(\mathrm{v} / \mathrm{v})$ $\mathrm{H}_{2} \mathrm{SO}_{4}$. Fractions were identified by comparison with authentic samples and by the use of specific reagents (Dittmer \& Lester, 1964; Siakotos \& Rouser, 1965; Vioque, 1984). Lipids were quantified densitometrically using a Beckman R-112 densitometer.

Methanolysis of total lipids was achieved by heating at $90{ }^{\circ} \mathrm{C}$ with $2 \%(\mathrm{v} / \mathrm{v}) \mathrm{H}_{2} \mathrm{SO}_{4}$ in absolute methanol (Chalvardjian, 1964). Following extraction with hexane, the resulting fatty acid methyl esters were purified by TLC and were analysed by GLC using a Pye-Unicam 204 chromatograph with a glass column $(1.83 \mathrm{~m} \times 4 \mathrm{~mm}$ i.d.) packed with $15 \%(w / w)$ DEGS on Anakron $D\left(100-120\right.$ mesh) at $170^{\circ} \mathrm{C}$ with nitrogen as the carrier gas.

\section{RESULTS}

\section{Radial extension and production of biomass}

With increasing salinity above $5 \%$, a decrease in the growth rate was observed both for the linear extension and the biomass of all three isolates (Fig. 1 $a-d$ ). The Alternaria spp. produced the greatest biomass as well as linear extension with the linear extension of $A$. chlamydospora being inhibited more at higher salinities. $U$. chartarum was consistently the most affected by increasing salinity. Slight growth was recorded for the Alternaria spp. on $15 \% \mathrm{NaCl}$ media after a $7 \mathrm{~d}$ incubation period. A longer incubation period ( $21 \mathrm{~d}$ ) resulted in significant growth of $A$. 

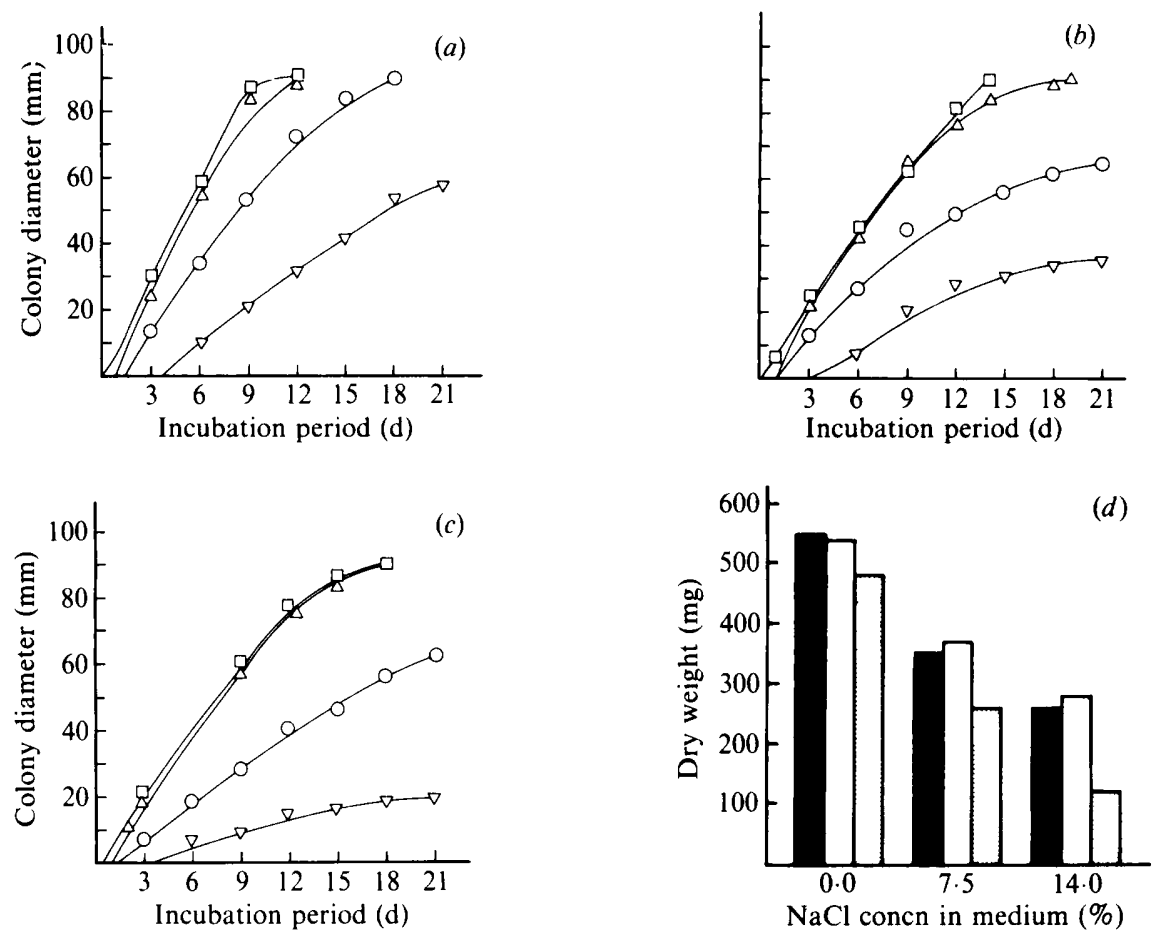

Fig. 1. Relative growth at different $\mathrm{NaCl}$ concentrations. (a) A. phragmospora; (b) A chlamydospora; (c) U. chartarum. $\square, \mathrm{No} \mathrm{NaCl} ; \triangle, 5 \%(\mathrm{w} / \mathrm{v}) \mathrm{NaCl} ; \bigcirc, 10 \%, \nabla, 15 \%$. (d) Production of biomass after $7 \mathrm{~d} ; \square$, A. phragmospora; $\square$, A. chlamydospora; , U. chartarum.

phragmospora $(58 \mathrm{~mm})$ and $A$. chlamydospora $(36 \mathrm{~mm})$. These values are much lower compared to the growth of $A$. phragmospora $(90 \mathrm{~mm})$ and $A$. chlamydospora $(65 \mathrm{~mm})$ in $10 \% \mathrm{NaCl} . U$. chartarum produced a $20 \mathrm{~mm}$ colony at $15 \% \mathrm{NaCl}$ whilst at $10 \%$ a diameter of $63 \mathrm{~mm}$ was recorded.

The biomass values for each isolate after a $7 \mathrm{~d}$ incubation period are compared in Fig. $1(d)$. Increasing salinity resulted in the expected decrease in biomass production in all three isolates, but this reduction was more gradual than that observed for radial extension. As for radial extension, $U$. chartarum exhibited greater sensitivity than the other two isolates, with a $75 \%$ biomass reduction at $14 \% \mathrm{NaCl}$, whereas the reductions in the biomass of $A$. phragmospora and A. chlamydospora were $52 \%$ and $48 \%$ respectively.

\section{Cell structure}

Light microscopy and SEM studies revealed a substantial alteration in the overall structure and morphology of the isolates. There was a progressive trend from the typical thin-walled sporulating mycelium in the absence of $\mathrm{NaCl}$ to the thick-walled, chlamydosporic mycelial form with few or no conidia. The mycelial cells became larger with increasing salinity, whilst septation became more pronounced and more frequent. This resulted in the formation of large thick-walled cells in cultures grown in $14 \% \mathrm{NaCl}$ (Figs 2 and 3). Conidiogenesis, which is usually prolific in these isolates, was greatly inhibited by concentrations of $\mathrm{NaCl}>5 \%$ (data not shown). The SEM studies confirmed the increased frequency of septation (Fig. 4).

\section{Lipid composition}

The composition of the lipid classes in the isolates grown in varying salinities are shown in Table 1 and in Figs 5 and 6 . The lipid classes in the apolar fractions were mainly steryl esters and fatty acids, followed by sterols, hydrocarbons and diglycerides. The latter were not, however, 

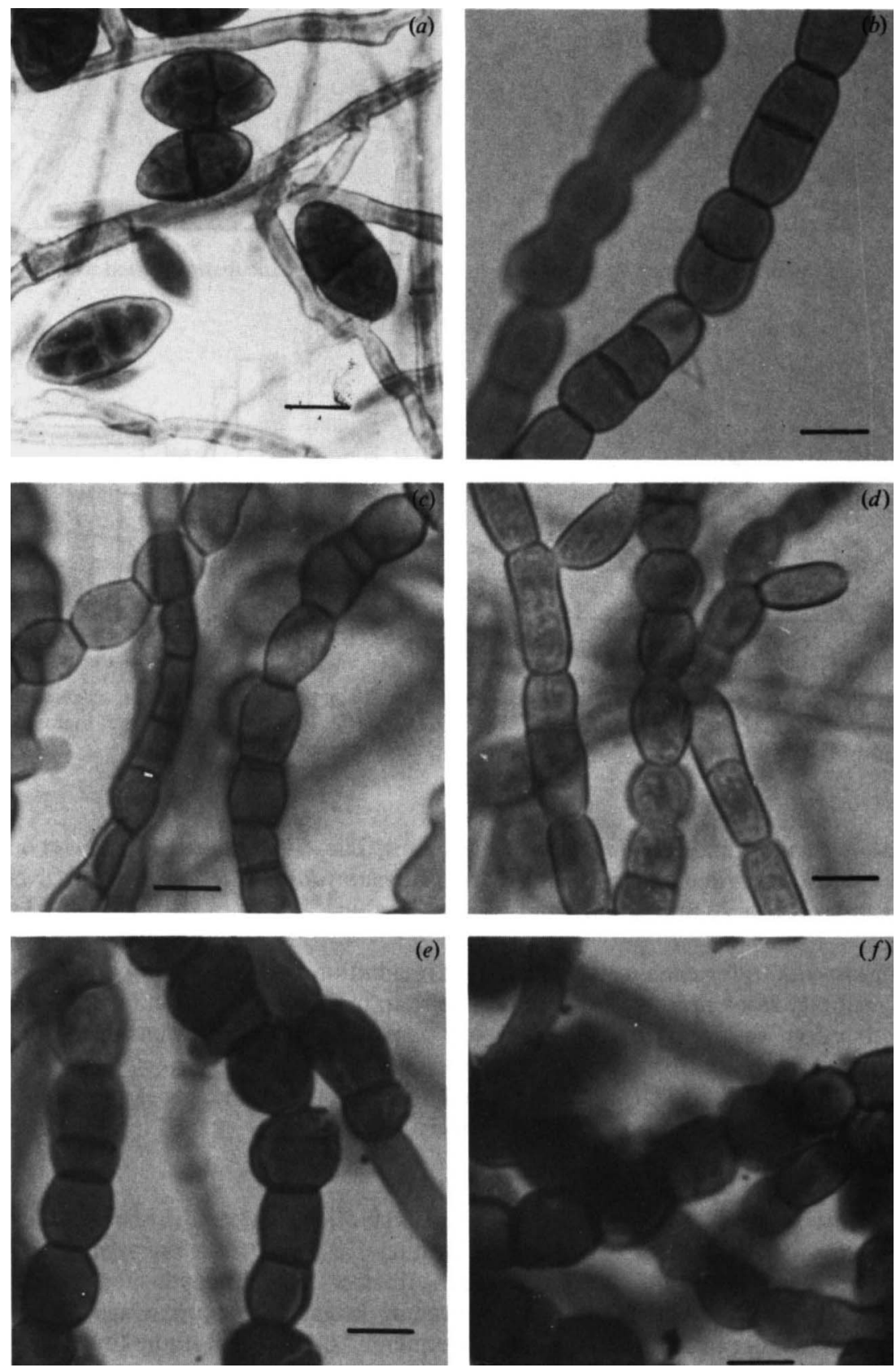

Fig. 2. Photomicrographs of mycelium of $U$. chartarum grown at different concentrations of $\mathrm{NaCl}$. (a) $\mathrm{No} \mathrm{NaCl}$ - thin-walled mycelium with typical dictyospores; (b) $5 \%(\mathrm{w} / \mathrm{v}) \mathrm{NaCl} ;(c) 7 \cdot 5 \% ;(d) 10 \% ;(e)$ $12 \% ;(f) 14 \%$. Note the increasing frequency of septation resulting in mycelium with inflated cells. Bar, $10 \mu \mathrm{m}$. 

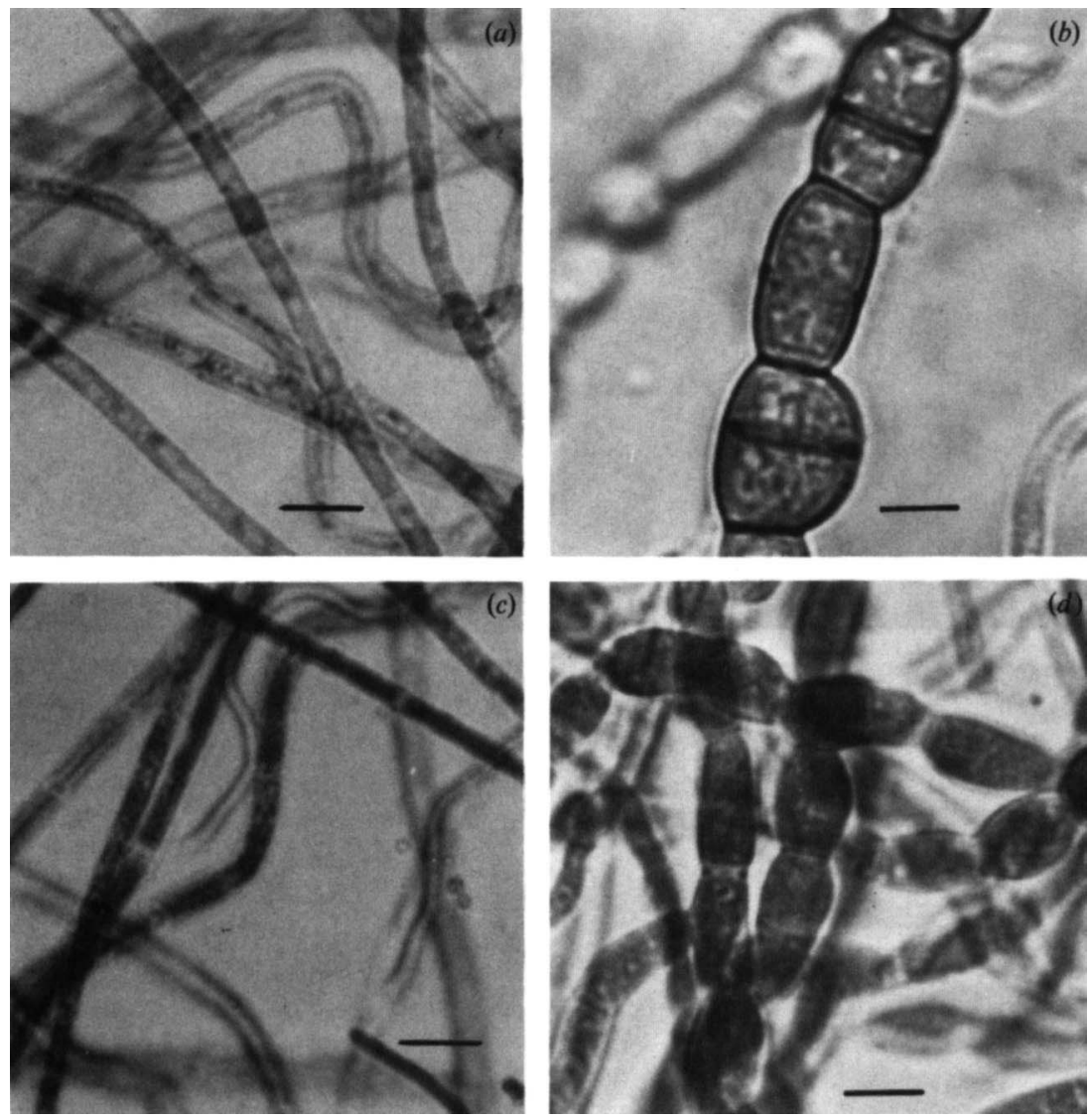

Fig. 3. Photomicrographs of $A$. phragmospora $(a, b)$ and $A$. chlamydospora $(c, d)$. Cultures were grown without $\mathrm{NaCl}(a, c)$ or at $10 \% \mathrm{NaCl}(b, d)$. Bar, $10 \mu \mathrm{m}$.

detected in $A$. chlamydospora. Similarly, 1- and 2-monoglycerides were present only in trace amounts in the latter species, whereas in $A$. phragmospora and $U$. chartarum significant increases were recorded in $10 \% \mathrm{NaCl}$. The sterols in all the isolates increased at the higher salinity. The main polar compounds recorded at significant levels in the three isolates were phospholipids including phosphatidylethanolamine, phosphatidylglycerol and phosphatidylcholine. All phospholipids decreased in the isolates grown at the higher salinity, except for phosphatidylcholine which increased slightly in $A$. phragmospora. Ceramide monohexoside was the major glycolipid present. Cardiolipin was detected in all the isolates and at different salinities. Monogalactosyldiacylglycerol and digalactosyldiacylglycerol occurred in small amounts.

The constituent fatty acids of the total lipids from each isolate grown at the different salinities are given in Table 2 . In all isolates oleic acid $(18: 1)$ was the major fatty acid, and its porportion decreased at higher salinity. A similar pattern was observed for palmitic acid (16:0). Linoleic acid $(18: 2)$ in $A$. chlamydospora and $U$. chartarum increased very markedly at higher salinity, whereas in $A$. phragmospora there was a decrease. Myristic acid (14:0) and myristoleic acids $(14: 1,14: 2)$ were detected in all isolates at the higher salinity, but only in trace amounts in the absence of $\mathrm{NaCl}$.

The results in Table 3 show some lipid classes and their fatty acid patterns. The predominant fatty acid for the individual classes was $18: 1$ when the organisms were cultured in the absence of $\mathrm{NaCl}$. The saturated 16:0 and polyunsaturated 18:2 fatty acids also occurred in significant amounts in the lipid classes. In most lipid classes $18: 1$ decreased with the increase in salinity. 

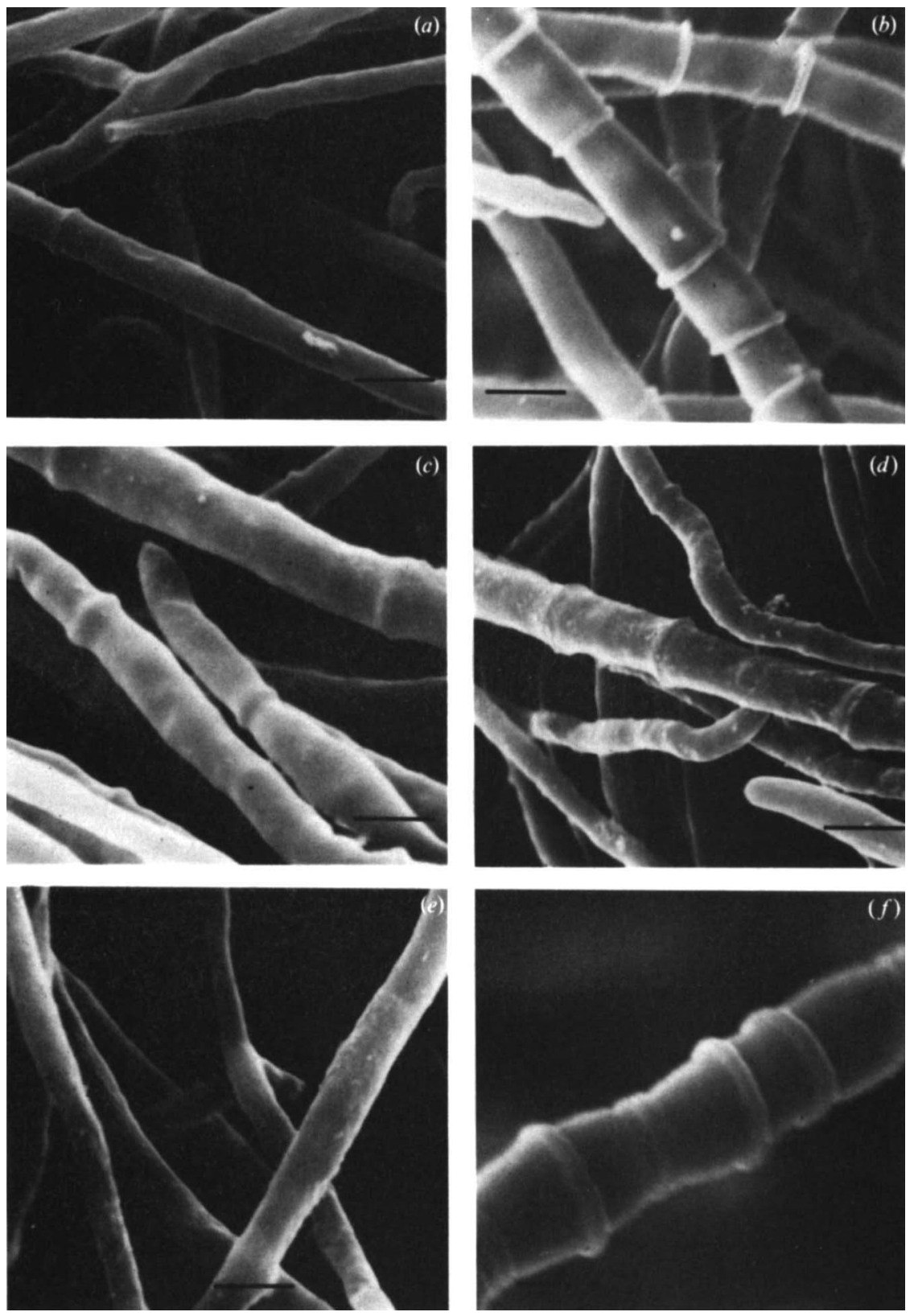

Fig. 4. Scanning electron micrographs of the fungal isolates demonstrating increased septation at $10 \%$ $\mathrm{NaCl} .(a, b)$ A. phragmospora, no $\mathrm{NaCl}$ and $10 \% \mathrm{NaCl} ;(c, d), A$. chlamydospora, no $\mathrm{NaCl}$ and $10 \%$ $\mathrm{NaCl} ;(e, f) U$. chartarum, no $\mathrm{NaCl}$ and $10 \% \mathrm{NaCl}$. 
Table 1. Composition of lipid classes from the fungal isolates grown at different salinities

Values are expressed as the percentage $(w / w)$ of the total amount of lipid and are the means \pm SD of three determinations. ND, Not detected; Tr., trace; Control, no $\mathrm{NaCl}$.

Relative amounts $(\%, w / w)$

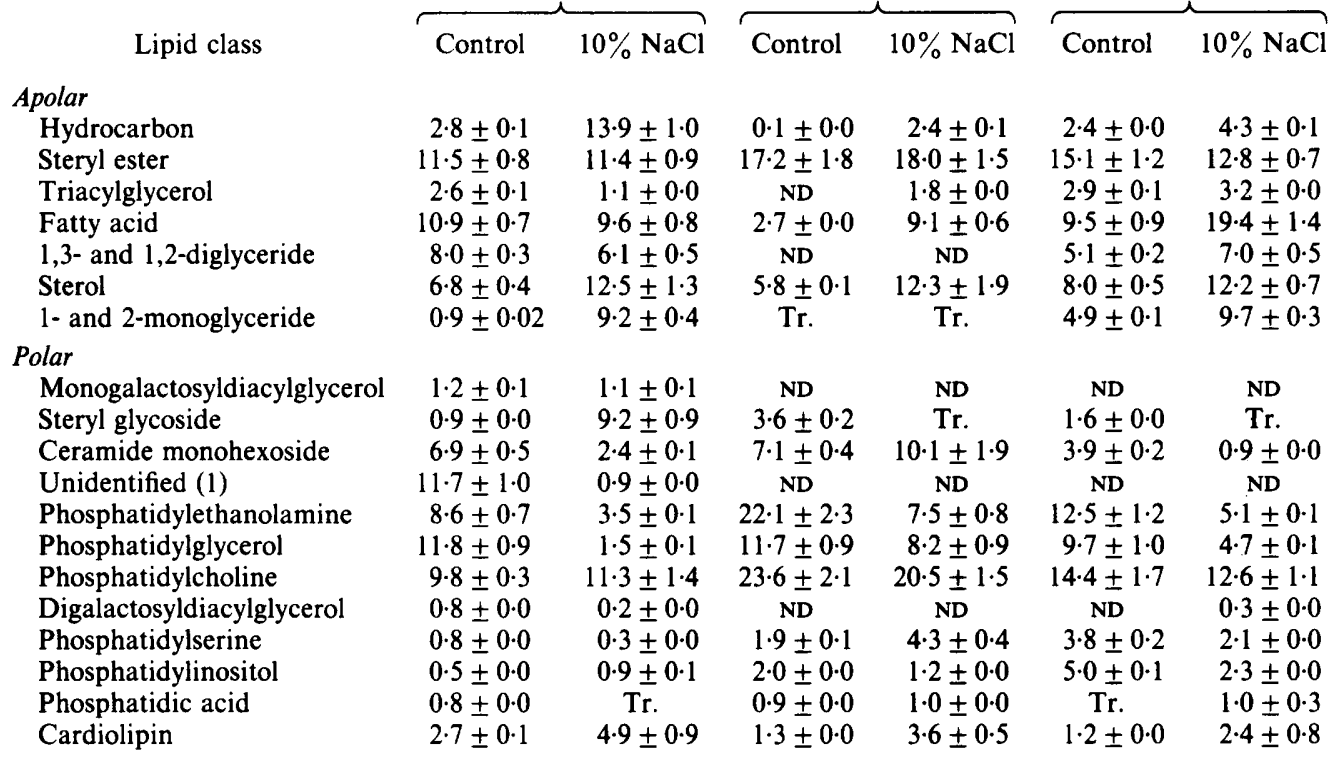

Table 2. Constituent fatty acids of total lipids from the fungal isolates grown at different salinities

Values are expressed as the percentage ( $w / w)$ of the total amount of lipid and are the means \pm SD of three determinations. ND, Not detected; Tr., trace; Control, no $\mathrm{NaCl}$.

Relative amounts $(\%, w / w)$

\begin{tabular}{|c|c|c|c|c|c|c|}
\hline Fatty acid & Control & $10 \% \mathrm{NaCl}$ & Control & $10 \% \mathrm{NaCl}$ & Control & $10 \% \mathrm{NaCl}$ \\
\hline$<14$ & $0.4 \pm 0.0$ & $2 \cdot 0 \pm 0 \cdot 1$ & $0.6 \pm 0.0$ & $1 \cdot 2 \pm 0.0$ & $0.65 \pm 0.1$ & $0.4 \pm 0.0$ \\
\hline $14: 0$ & $3.9 \pm 0.3$ & $8.0 \pm 0.7$ & $0.8 \pm 0.1$ & $2 \cdot 6 \pm 0.0$ & $0.14 \pm 0.0$ & $0.1 \pm 0.0$ \\
\hline $14: 1$ & $\mathrm{Tr}$ & $4 \cdot 3 \pm 0.0$ & $2 \cdot 1 \pm 0.0$ & $3.2 \pm 0.0$ & Tr. & $4.6 \pm 0.2$ \\
\hline $14: 2$ & ND & $4 \cdot 7 \pm 0.0$ & Tr. & $2 \cdot 3 \pm 0.1$ & Tr. & $3.2 \pm 0.1$ \\
\hline $16: 0$ & $19 \cdot 3 \pm 1 \cdot 0$ & $11 \cdot 2 \pm 0.9$ & $21 \cdot 1 \pm 1 \cdot 1$ & $17 \cdot 6 \pm 1 \cdot 3$ & $29.6 \pm 1.9$ & $17 \cdot 3 \pm 1 \cdot 3$ \\
\hline $16: 1$ & Tr. & $7 \cdot 4 \pm 0.8$ & $0.2 \pm 0.0$ & $3.7 \pm 0.1$ & Tr. & $7 \cdot 1 \pm 1.0$ \\
\hline $18: 0$ & $5 \cdot 2 \pm 0 \cdot 0$ & $6 \cdot 3 \pm 0 \cdot 1$ & $5.5 \pm 0.0$ & $3.5 \pm 0.5$ & $3.6 \pm 0.2$ & $0.5 \pm 0.1$ \\
\hline $18: 1$ & $56 \cdot 9 \pm 3 \cdot 1$ & $42 \cdot 0 \pm 2 \cdot 3$ & $65 \cdot 1 \pm 4 \cdot 7$ & $25.5 \pm 1.8$ & $45 \cdot 1 \pm 3 \cdot 1$ & $26.5 \pm 1.8$ \\
\hline $18: 2$ & $10.6 \pm 0.9$ & $3 \cdot 6 \pm 0.1$ & $1.2 \pm 0.0$ & $34 \cdot 3 \pm 2 \cdot 0$ & $12.6 \pm 0.9$ & $30 \cdot 3 \pm 2 \cdot 1$ \\
\hline $18: 3$ & $2 \cdot 2 \pm 0.0$ & $1.7 \pm 0.1$ & $0.2 \pm 0.0$ & $1 \cdot 5 \pm 0.0$ & $8 \cdot 3 \pm 0.2$ & $10 \cdot 0 \pm 1 \cdot 1$ \\
\hline$>18$ & $1.5 \pm 0.0$ & $5 \cdot 8 \pm 0.1$ & $3.3 \pm 0.3$ & $4 \cdot 6 \pm 0.1$ & Tr. & $\mathrm{Tr}$ \\
\hline
\end{tabular}

This trend was reversed for 18:2 which increased in the major polar compounds (phosphatidylglycerol, phosphatidylethanolamine and phosphatidylcholine), the one exception being phosphatidylcholine in $A$. phragmospora. Significant decreases in the saturated fatty acid $16: 0$ were recorded in phosphatidylglycerol in $U$. chartarum and $A$. chlamydospora as well as in 


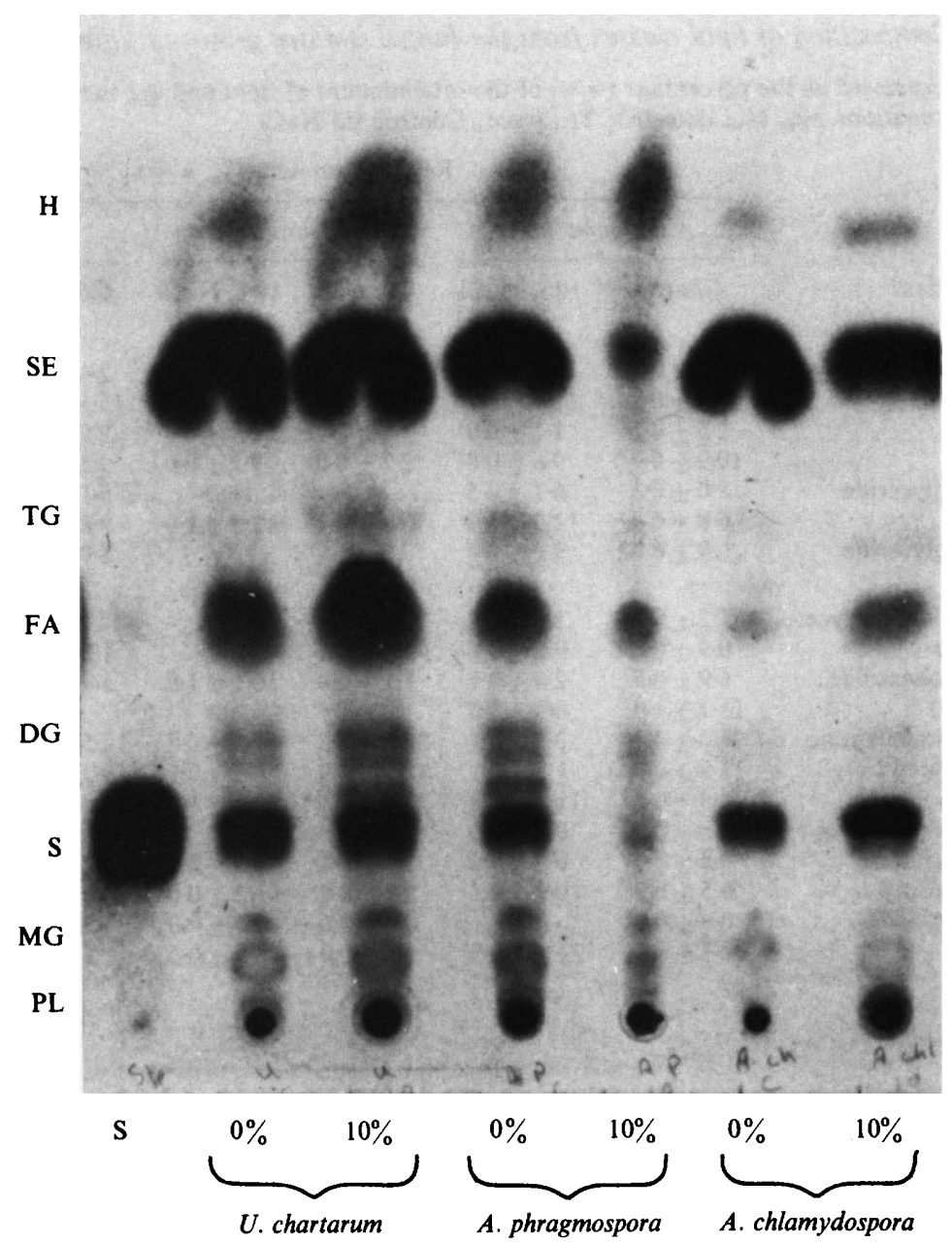

Fig. 5. Thin-layer chromatographic separation of the apolar lipids of $U$. chartarum, A, phragmospora and $A$. chlamydospora grown at the indicated $\mathrm{NaCl}$ concentration. Lipids were visualized by exposure to iodine vapour. $\mathrm{H}$, hydrocarbon; SE, steryl esters; TG, triacylglycerols; FA, fatty acids; DG, diglycerides; S, sterols; MG, monoglycerides; PL, polar lipids.

phosphatidylethanolamine in $A$. phragmospora and $U$. chlamydospora. The unsaturated $16: 1$ occurred in trace amounts or was not detected in the major polar compounds of the isolates grown without $\mathrm{NaCl}$, but appeared in significant amounts in the isolates grown at the higher salinity.

Fig. 6. Two-dimensional thin-layer chromatograms showing the composition of polar lipid classes for the three isolates grown without $\mathrm{NaCl}$ and at $10 \% \mathrm{NaCl} .(a, b) U$. chartarum, no $\mathrm{NaCl}$ and $10 \% \mathrm{NaCl}$; $(c, d) A$. chlamydospora, no $\mathrm{NaCl}$ and $10 \% \mathrm{NaCl} ;(e, f) A$. phragmospora, no $\mathrm{NaCl}$ and $10 \% \mathrm{NaCl}$. TLC was done using silica gel plates and the following solvent systems: chloroform $/ \mathrm{methanol} / 7 \mathrm{M}$ ammonium hydroxide $(65: 30: 4$, by vol.) in the first dimension and chloroform/methanol/acetic acid/water $(170: 25: 25: 4$, by vol.) in the second dimension. The lipid fractions were visualized by charring after spraying with $50 \%(\mathrm{v} / \mathrm{v}) \mathrm{H}_{2} \mathrm{SO}_{4}$. MGDG, monogalactosyldiacylglycerol; SG, steryl glycoside; $\mathrm{CMH}$, ceramide monohexoside; $\mathrm{PE}$, phosphatidylethanolamine; $\mathrm{PG}$, phosphatidylglycerol; PC, phosphatidylcholine; PS, phosphatidylserine; PI, phosphatidylinositol; PA, phosphatidic acid; CL, cardiolipin. 

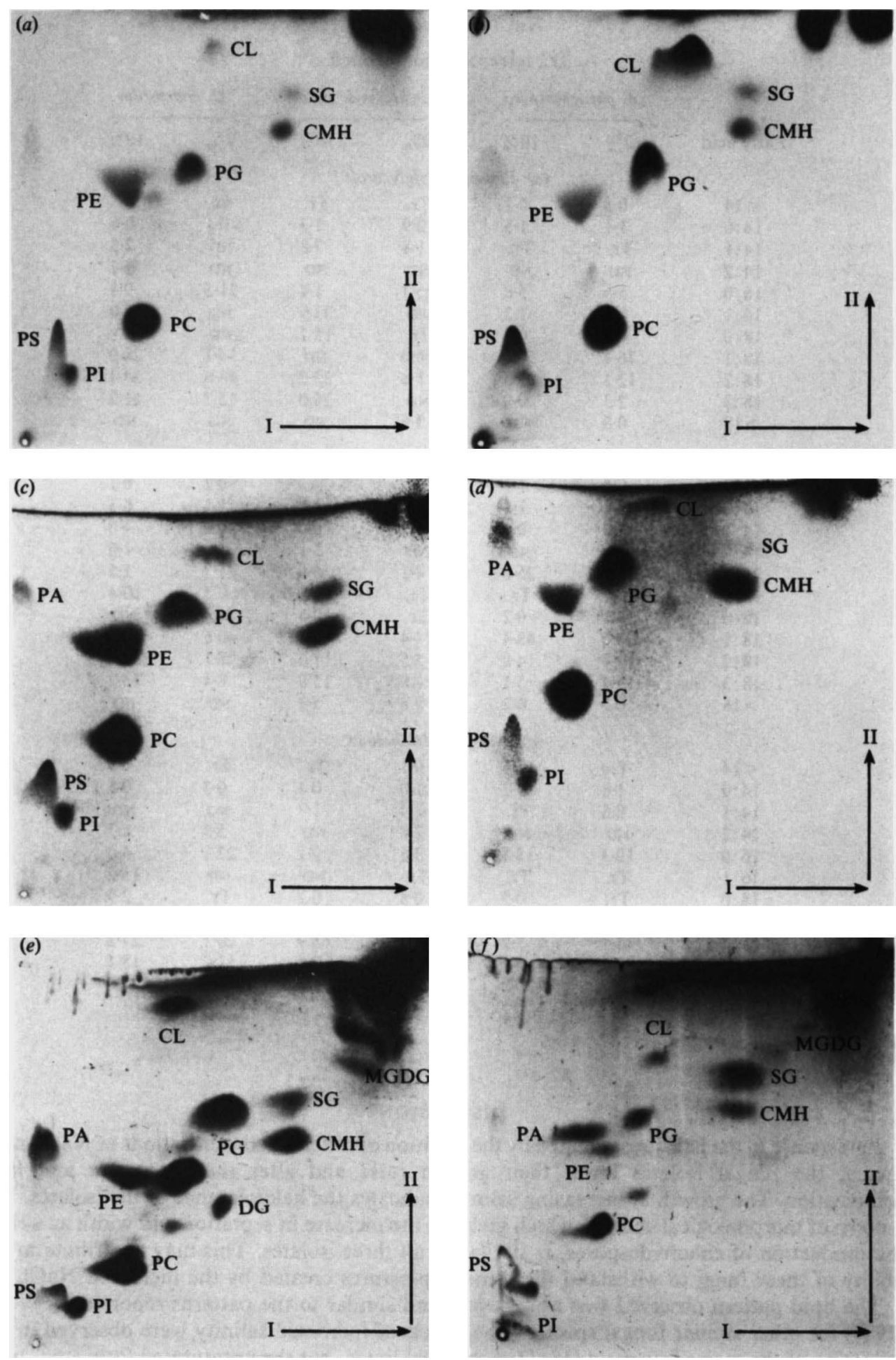
Table 3. Fatty acid patterns of some lipid classes from the fungal isolates grown at different $\mathrm{NaCl}$ concentrations

Tr., trace; ND, Not detected.

\begin{tabular}{|c|c|c|c|c|c|c|}
\hline \multirow[b]{2}{*}{ Fatty acid } & \multicolumn{2}{|c|}{ A. phragmospora } & \multicolumn{2}{|c|}{ A. chlamydospora } & \multicolumn{2}{|c|}{ U. chartarum } \\
\hline & $0 \%$ & $10 \%$ & $0 \%$ & $10 \%$ & $0 \%$ & $10 \%$ \\
\hline \multicolumn{7}{|c|}{ (a) Phosphatidylglycerols } \\
\hline$<14$ & 0.5 & $0 \cdot 1$ & Tr. & Tr. & ND & Tr. \\
\hline $14: 0$ & $1 \cdot 1$ & 1.8 & 0.9 & $1 \cdot 3$ & $0 \cdot 1$ & 0.6 \\
\hline $14: 1$ & Tr. & Tr. & 1.8 & $7 \cdot 8$ & ND & $7 \cdot 5$ \\
\hline $14: 2$ & ND & ND & ND & ND & ND & $1 \cdot 1$ \\
\hline $16: 0$ & $6 \cdot 6$ & $5 \cdot 8$ & $25 \cdot 7$ & 1.4 & 31.5 & $9 \cdot 1$ \\
\hline $16: 1$ & $0 \cdot 1$ & $1 \cdot 3$ & ND & 23.9 & ND & $8 \cdot 0$ \\
\hline $18: 0$ & $0 \cdot 2$ & 0.3 & Tr. & $15 \cdot 7$ & ND & ND \\
\hline $18: 1$ & $76 \cdot 4$ & 50.7 & $66 \cdot 0$ & ND & $34 \cdot 1$ & $28 \cdot 0$ \\
\hline $18: 2$ & $12 \cdot 1$ & $39 \cdot 3$ & 1.8 & 23.9 & 18.6 & $34 \cdot 4$ \\
\hline $18: 3$ & $2 \cdot 3$ & 0.9 & ND & $26 \cdot 0$ & $15 \cdot 7$ & $11 \cdot 2$ \\
\hline$>18$ & 0.8 & ND & 3.6 & ND & ND & ND \\
\hline \multicolumn{7}{|c|}{ (b) Phosphatidylethanolamines } \\
\hline$<14$ & 0.6 & $1 \cdot 1$ & Tr. & Tr. & $0 \cdot 2$ & $0 \cdot 1$ \\
\hline $14: 0$ & $1 \cdot 7$ & $1 \cdot 0$ & 1.9 & 1.5 & $1 \cdot 1$ & $0 \cdot 3$ \\
\hline $14: 1$ & $4 \cdot 3$ & 0.1 & $6 \cdot 3$ & $6 \cdot 0$ & ND & $4 \cdot 0$ \\
\hline $14: 2$ & ND & ND & ND & $5 \cdot 1$ & ND & 1.6 \\
\hline $16: 0$ & $33 \cdot 1$ & $25 \cdot 0$ & $4 \cdot 1$ & 6.6 & $21 \cdot 2$ & 1.5 \\
\hline $16: 1$ & Tr. & Tr. & Tr. & $20 \cdot 1$ & 0.5 & $10 \cdot 4$ \\
\hline $18: 0$ & $3 \cdot 1$ & 0.2 & Tr. & $10 \cdot 6$ & ND & ND \\
\hline $18: 1$ & $40 \cdot 6$ & $48 \cdot 4$ & $74 \cdot 4$ & $9 \cdot 7$ & $40 \cdot 6$ & $30 \cdot 0$ \\
\hline $18: 2$ & $10 \cdot 7$ & $14 \cdot 0$ & 3.5 & 17.6 & $28 \cdot 1$ & $39 \cdot 0$ \\
\hline $18: 3$ & $5 \cdot 4$ & $5 \cdot 1$ & ND & 15.9 & 8.4 & $13 \cdot 2$ \\
\hline$>18$ & 0.5 & $6 \cdot 2$ & 9.8 & 5.9 & ND & ND \\
\hline \multicolumn{7}{|c|}{ (c) Phosphatidylcholines } \\
\hline$<14$ & 0.4 & $1 \cdot 2$ & $0 \cdot 1$ & Tr. & Tr. & 0.2 \\
\hline $14: 0$ & 1.6 & $5 \cdot 3$ & $1 \cdot 0$ & 0.4 & $0 \cdot 3$ & 0.5 \\
\hline $14: 1$ & $0 \cdot 6$ & Tr. & 1.4 & 1.7 & ND & ND \\
\hline $14: 2$ & ND & ND & $2 \cdot 8$ & ND & $5 \cdot 3$ & $8 \cdot 7$ \\
\hline $16: 0$ & $12 \cdot 3$ & $15 \cdot 1$ & 3.6 & $9 \cdot 1$ & $22 \cdot 1$ & 4.0 \\
\hline $16: 1$ & Tr. & Tr. & Tr. & ND & ND & $15 \cdot 2$ \\
\hline $18: 0$ & Tr. & 0.5 & 0.8 & 0.2 & Tr. & 2.9 \\
\hline $18: 1$ & $70 \cdot 2$ & 47.0 & $73 \cdot 5$ & $20 \cdot 2$ & $41 \cdot 2$ & 22.9 \\
\hline $18: 2$ & $13 \cdot 1$ & $7 \cdot 7$ & 11.8 & 65.9 & $20 \cdot 1$ & $27 \cdot 2$ \\
\hline $18: 3$ & 1.7 & $3 \cdot 2$ & ND & 2.5 & $11 \cdot 0$ & 18.4 \\
\hline$>18$ & $0 \cdot 2$ & $20 \cdot 0$ & 5.0 & ND & ND & ND \\
\hline
\end{tabular}

\section{DISCUSSION}

In response to the halostress created by the addition of different concentrations of $\mathrm{NaCl}$ in the media, the fungal isolates lower their growth rates and alter their structure and lipid composition. The growth at increasing salinity indicates the halotolerance of the isolates. The pattern of morphological change, which includes the increase in septation and width as well as the production of chlamydospores, is similar in all three isolates. This may contribute to the ability of these fungi to withstand the osmotic pressures created by the increased $\mathrm{NaCl}$.

The lipid pattern observed was as expected and similar to the patterns reported by Weete (1980) for other similar fungal species. The effects of increased salinity were observed in the reduction of the major fatty acid $(18: 1)$ of the total lipids, but the unsaturated fatty acids were greater than the saturated fatty acids. This is consistent with the effects of salinity on lipids of $C$. albicans (Combs et al., 1968). Phosphatidylethanolamine and phosphatidylglycerol decrease and 
cardiolipin increases with the increase of $\mathrm{NaCl}$ in the growth medium, which may be a specific response to $\mathrm{NaCl}$ or may result from changes in growth rate. The scarcity of studies on similar eukaryotic organisms makes comparison difficult. Investigations which are reported are those which deal with prokaryotic organisms. Haloadaptive responses in prokaryotes may be very different to those in eukaryotes, as the organisation of a prokaryote is different. However, Miller (1985) did report a similar response for the halotolerant bacterium Planococcus. Adams et al. (1987) reported that phosphatidylethanolamine synthesis is reduced after increases in $\mathrm{NaCl}$ concentration. These $\mathrm{NaCl}$-induced changes in lipid composition may control the ionic permeability of the organism in high salinity conditions (Ohno et al., 1976, 1979). The similar responses observed in the present study suggest that lipids may play a role in regulating membrane permeability at different salinities.

The authors with to thank Mr S. Rajendra for his technical assistance and the staff of the Electron Microscope Unit, Kuwait University. This investigation was supported by Kuwait University, Research Management Unit, projects RA 0046 and S0038.

\section{REFERENCES}

ADAms, R., Bygraves, J., Kogut, M. \& Russell, N. J. (1987). The role of osmotic effects in haloadaptation of Vibrio costicola. Journal of General Microbiology 133, 1861-1870.

Al-Hasan, R. H., Ghannoum, M. A., Sallal, A. K., Abu-Elteen, K. H. \& Radwan, S. S. (1987). Correlative changes of growth, pigmentation and lipid composition of Dunaliella salina in response to halostress. Journal of General Microbiology 133, 2607-2616.

AVron, M. \& Ben-Amotz, AW. (1979). Metabolic adaptation of the alga Dunaliella to low water activity. In Strategies of Microbial Life in Extreme Environments, pp. 83-91. Edited by M. Shilo. Berlin: Dahlem Konferenzen.

Brown, A. D. (1972). Microbial water relations: features of the intracellular composition of sugartolerant yeasts. Journal of Bacteriology 118, 769-777.

Brown, A. D. (1976). Microbial water stress. Bacteriology Reviews 40, 803-846.

Chalvardian, V. (1964). Fatty acids of brown and yellow fat in rats. Biochemical Journal 90, 518521.

Cole, G. T. (1986). Preparation of microfungi for scanning electron microscopy. In Ultrastructure Techniques for Micro-organisms, pp. 1-38. Edited by H. C. Aldrich \& W. J. Todd. New York: Plenum Press.

Combs, T. J., Guarneri, J. J. \& Pisano, M. A. (1968). The effect of sodium chloride on the lipid content and fatty acid composition of Candida albicans. Mycologia 60, 1232-1239.

DitTMER, J. C. \& Lester, R. L. (1964). A simple specific spray for the detection of phospholipids on thin layer chromatograms. Journal of Lipid Research 5, 126-127.

Folch, J., Lees, M. \& Sloane Stanley, G. H. (1957). A simple method for the isolation and purification of total lipids from animal tissue. Journal of Biological Chemistry 226, 497-509.

Grant, W. D. \& LoNG, P. E. (1981). Environmental Microbiology. London: Blackie.

KUSHNER, D. J. (1978). Microbial Life in Extreme Environments. New York: Academic Press.
Mangold, H. K. \& Malins, D. C. (1960). Fractionation of fats, oils and waxes on thin layers of silicic acid. Journal of the American Oil Chemists Society 37, 383-385.

MilleR, K. J. (1985). Effects of temperature and sodium chloride concentration on the phospholipid and fatty acid composition of a halotolerant Planococcus sp. Journal of Bacteriology 162, 263-270.

Moustafa, A. F. (1975). Osmophilous fungi in the salt marshes of Kuwait. Canadian Journal of Microbiology 21, 1573-1580.

Nichols, B. W. (1964). Separation of plant phospholipids and glycolipids. In New Biochemical Separations. Edited by A. T. James \& I. J. Morris. London: Van Nostrand.

NoRRIS, J. R. \& RibBons, D. W. (1970). Methods in Microbiology 3A, 122.

Ohno, Y., Yano, I., Hiramatsu, T. \& Masui, M. (1976). Lipids and fatty acids of a moderately halophilic bacterium no. 101. Biochimica et biophysica acta 424, 337-350.

OHNo, Y., Yano, I. \& Masui, M. (1979). Effect of $\mathrm{NaCl}$ concentration and temperature on the phospholipid and fatty acid composition of a moderately halophilic bacterium, Pseudomonas halosaccarolytica. Journal of Biochemistry 85, 413-421.

Paton, F. M. \& Jennings, D. H. (1988). Effect of sodium and potassium chloride and polyols on malate and glucose-6-phosphate dehydrogenases from the marine fungus Dendryphiella salina. Transactions of the British Mycological Society 91, 205-215.

Pugh, G. J. F. (1962). Studies of fungi in coastal soils. II. Fungal ecology in a developing salt marsh. Transactions of the British Mycological Society 45, 560-566.

Radwan, S. S., El-Essawy, A. A. \& Helal, G. A. (1984). Salinity loving fungi in Egyptian soils. I. Numbers, identification and halophilism. Zentralblatt für Mikrobiologie 139, 435 440.

Siakotos, A. N. \& Rouser, G. (1965). Analytical separation of non-lipid water soluble substances and gangliosides from other lipids by dextran gel column chromatography. Journal of the American Oil Chemists Society 42, 913-919. 
TReSner, H. D. \& Hayes, I. A. (1971). Sodium chloride tolerance of terrestrial fungi. Applied Microbiology 22, 210-213.

Vioque, E. (1984). Spray reagents for thin layer chromatography (TLC) and paper chromatography (PC). In Handbook of Chromatography, pp. 309-317. Edited by H. K. Mangold. Boca Raton, Florida: CRC Press.
WeETE, J. D. (1980). Lipid Biochemistry of Fungi and Other Organisms. New York: Plenum Press.

Wethered, J. M., MetCalf, E. C. \& Jennings, D. H. (1985). Carbohydrate metabolism in the fungus Dendryphiella salina. VIII. The contribution of polyols and ions to the mycelial solute potential in relation to external osmoticum. New Phytologist 101, 631-649. 